\title{
Arte Sensorial e o sentido nu
}

Cecília de Lima

Universidade de Lisboa

\section{Resumo}

Este artigo investiga a prática de sentidos emergentes da percepção de corpo em devir, propondo a noção de Arte Sensorial. Baseando-se na apologia do sensório para uma abordagem crítica e estética defendida por Susan Sontag, na noção de imagem nua de José Gil, na noção de afeto descrita por Brian Massumi e nos estudos sobre consciência de António Damásio e Gerald Edelman, o conceito de Arte Sensorial é aqui fundamentado enquanto um modo de produção de sentidos que ocorre através de uma percepção de afetos e micromovimentos em vez de signos de comunicação pré-determinados. Este conceito é então exemplificado através da análise da peça $A+B=X$ de Gillles Jobin e por fim, através do confronto entre esta análise com um artigo de Una Bauer que analisa a peça Jérôme Bel de Jérôme Bel, fundamenta-se a possibilidade de um grau zero de sentido intrínseco a Arte Sensorial.

Palavras-chave: Arte Sensorial. Corpo. Micromovimentos. Percepção. Sentido Nu.

\section{Introdução}

Atualmente, com a hibridização artística e a influência das ciências de "embodied cognition", a procura de sentidos tornou-se um jogo multifacetado e desafiante, aberto a novos potenciais e a novos modos de conceber sentido. Enquanto no passado a procura de sentidos nas artes performativas seria algo relativamente uniforme, pois a índole de sentidos era considerada maioritariamente de natureza linguística e narrativa, à qual se acrescentava o simbolismo e a representação, hoje em dia, a noção de sentido dramatúrgico é, tal como Ana Pais (2016) enfatiza, um conceito polissémico em ebulição académica e criativa. "A dramaturgia comete infrações na ordem estabelecida pelo visível, transformando-o e constituindo-o por renovadas articulações de sentido" (ibidem, p.21). Na prática artística contemporânea o conceito de dramaturgia deixou de estar apenas associado à produção de sentido baseada no texto cénico, tendo vindo a expandir-se enquanto uma prática de estudo de sentido onde se revelam também outros modos gerar de sentido: desde as novas tecnologias multimídia à mais antiga de todas - a corporeidade. Enquanto as novas tecnologias multimídia desafiam a corporeidade para arquitetar sentidos sobre relações ainda desconhecidas, as artes performativas e as ciências cognitivas vêm colocar os sentidos 
sensoriomotores e a percepção somática no centro da criação primária de sentido, sugestionando uma redescoberta de sentidos intrínsecos ao próprio processo de corpo em devir. Esta procura de sentido pelos sentidos sensoriais é um exercício intrínseco à criação e recepção artística.

As criações e pesquisas artísticas e académicas sobre o modo como experienciamos e concebemos sentido a partir da nossa relação com o mundo, vêm abrir todo um novo potencial intrínseco á própria lógica do pensamento (DE LIMA, 2017). Este artigo resulta de uma investigação sobre um modo de praticar sentido, modo esse que chamo de Arte Sensorial, a qual procura sentido(s) que emergem da percepção somática e sensoriomotora, tentando suspender interpretações intelectuais e pré-concebidas. Como ponto de partida, o conceito de Arte Sensorial investiga o emergir de sentido através do que José Gil (2005) chama de imagem nua, indo ao encontro de Susan Sontag no seu livro Against Interpretation, ao anunciar: "And it is in the light of the condition of our senses, our capacities [...], that the task of the critic must be assessed. [...] What is important now is to recover our senses. We must learn to see more, to hear more, to feel more" (SONTAG, 2001, p. 10).

O texto é composto por três momentos principais. Num primeiro momento tece diversas considerações teóricas que fundamentam a noção de Arte Sensorial e percepção nua. A noção de Arte Sensorial é de seguida posta em prática através do exercício de análise da obra $A+B=X$ do coreógrafo suíço Gilles Jobin, o qual procura o sentido da experiência estética da obra essencialmente através das percepções sensoriais e do afecto gerado pelos estímulos sensoriomotores. O terceiro e último momento apresenta uma confrontação entre a análise anterior da obra de Giles Jobin e o artigo de Una Bauer (2008), intitulado: The Movement of Embodied Thought The Representational Game of the Stage Zero of Signification in Jérôme Bel, o qual faz uma análise da peça Jérôme Bel, criada pelo coreógrafo Jèrôme Bel em 1995. Através desta comparação a noção de Arte Sensorial é aprofundada fundamentando-se a possibilidade de um grau zero de sentido, enquanto um modo de sentido pulsante que não se fixa na dicotomia sujeito-objeto e que se dá a sentir pelos micromovimentos da percepção.

\section{Arte Sensorial: a dança da percepção}

O conceito de Arte Sensorial procura a capacidade de aprofundar uma percepção emergente de sentido. Deste modo, o trabalho que aqui exponho faz uma investigação da percepção estética, na qual se salienta e aprofunda um logos do sentido sensorial. Diria então que este exercício caracteriza-se essencialmente como prática perceptiva que trabalha uma intensificação sensoriomotora, através da qual a realidade se torna percecionada como uma condição de movimento; tal como Daniel Lepkoff (2001) menciona, ao descrever a prática de Contact Improvisation, este exercício envolve 
an intensively physical state of questioning without an emergency situation to force me to do so. I discovered that in order to accomplish this task with no lapses of awareness, my intention need to be constantly in motion [...] When my attention stops moving, my interpretation of what is happening becomes fixed and my vision becomes conventionalised, and thus the questioning disappears (p. 40).

Ao esbater um reconhecimento pré-formatado ou pré-tensionado da realidade e fazer emergir um modo de atenção respirada, intuitiva das dinâmicas vitais, a realidade torna-se percebida como uma condição de movimento. Procura-se aqui incorporar o movimento corpomundo através do constante envolvimento sensorial. Ativada pelo estímulo de constantes mudanças, a percepção torna-se um incessante viajar no momento, e cada momento tornase uma vertigem no momentum. A Arte Sensorial investiga a percepção da realidade "as a continuous motion process happening in between the tension of temporary, formal dualities [...] by practicing a continuous flow of sensorial awareness, the gist of reality gains a motion quality" (DE LIMA, 2010, p. 178). Este exercício sensorial vem manifestar o carácter vibrante intrínseco á própria percepção, e, ao fazer tal, revela uma capacidade perceptiva que não se prende a pré-tensões, mas que se dança a si mesma, ou seja embrenha-se no seu movimento intrínseco - corpo-mundo. Diria então que é no sentir do sentido de um movimentar que se fomenta a si mesmo que ocorre uma percepção nua, onde se percepciona um grau zero de sentido, já como sentido sofrível e permeável. Por exemplo: a sensação intrínseca ao movimento de abrir os braços e expor o peito para cima gera em sim uma sensação de vulnerabilidade e de abertura do corpo e dos sentidos em relação ao seu meio envolvente; não é necessária uma interpretação preconcebida ou simbólica deste gesto para conceber o seu sentido. O sentido deste gesto surge enquanto experiência sensitiva do movimento corporal do próprio e pela empatia cinestésica (Reynolds and Reason, 2012) de quem o observa. Outro exemplo: um grito de um vocábulo impercetível não perde o seu sentido por não se conseguir distinguir esse vocábulo, o sentido desse grito surge da energia, do ímpeto e da qualidade do som inerente a esse grito.

\section{A PERCEPÇÃO VIRGEM, NUA E VESTIDA}

Esta noção de Arte Sensorial interliga-se com um modo perceptivo a que chamo percepção nua, pelo que, começo por trazer aqui algumas considerações partindo dos estudos sobre percepção de Gibson (1966) e da noção de imagem nua de José Gil (2005), para depois conceber este modo perceptivo à luz dos estudos neurocientíficos sobre consciência de Damásio (2010) e de Edelman (1992).

J. J. Gibson (1966) trouxe uma nova visão à abordagem clássica de percepção, demonstrando que a percepção é um processo ativo que envolve todo o ser em constante interação com o ambiente. Gibson destaca três aspetos principais: a) os sistemas perceptivos são mecanismos ativos para receber diferentes tipos de estímulos informativos do ambiente; 
b) estes sistemas perceptivos diversos funcionam em inter-relação; c) a percepção é baseada na capacidade de movimento. Estes estudos de Gibson demostram como a própria percepção é em si um mecanismo ativo intrínseco à relação corpo-mundo.

Abro aqui um parêntesis, para aprofundar um pouco a expressão corpo-mundo, que será essencial para uma melhor compreensão do texto que se segue. Corpo-mundo é uma expressão que desenvolvi na tese de doutoramento (DE LIMA, 2017), a qual se refere à noção de corpo vivo que manifesta sentido enquanto movimento de transformação e é percebido enquanto processo de afeto, através de uma vivência somática intensa. Afeto é aqui considerado no sentido de Deleuze, segundo Massumi (2002) - uma experiência pré-pessoal de intensidade intrínseca à necessidade de afetar e ser afetado. Massumi realça que o corpo é continuamente influenciado por milhares de estímulos, reagindo por um processo a que designa como infolding ${ }^{1}$, e percecionando este processo como intensidade. A dança pratica uma intensidade sensoriomotora na qual afeto é fisicamente experienciado como um processo de sobrevivência (percecionado logo ao nível da respiração), que surge de uma necessidade de afetar e ser afetado num feedback interativo entre um meio interno e externo. A percepção do corpo trespassa o seu limite material para intensificar o seu poder de vida como um processo de afeto uma necessidade intrínseca e intuitiva de absorver - incorporar o mundo e expelir - desincorporar-se no mundo e ser incorporado por ele. A percepção de corpo é então experienciada enquanto movimento de transformação, ele não é um corpo por si só, mas sim uma constante relação corpo-mundo.

José Gil (2005, p. 92) sugere que "toda a imagem a que falta o seu sentido verbal provoca um apelo ao sentido (como um vazio suscita um apelo ao ar)". O filósofo fala-nos da noção de imagem nua como a imagem despojada de conceito que faz um apelo ao sentido resultante de uma "dinâmica das forças pulsionais" (idem, p.96), acrescentando que, ao ser despojada de conceito, a imagem provoca uma espécie de desestruturação, transformandose em "matéria sensível que tende [...] a tornar-se forma pura como se, deixando de ser subsumida pelo conceito, a multiplicidade sensível, intensificando as suas qualidades, ganhasse uma pregnância perceptiva formal" (ibidem, p. 123). "As qualidades sensíveis intensificam-se como para compensar a falta de conceito" (ibidem). Ou seja, a imagem nua, é uma imagem "em estado livre" (ibidem, p. 122), que em que a própria forma não é totalmente formada, gerando assim um potencial de movimento transformativo intrínseco à própria imagem.

Ora, a concepção que aqui proponho parte desta noção de imagem nua, para considerar a noção de uma percepção nua enquanto um modo perceptivo que procura despojar-se de

1 Massumi usa o termo "infolding" para referir um corpo que no seu processo de devir absorve e desdobra sobre si próprio todos os estímulos/ informação que o envolve. 
preconceções de sentido, apelando assim ao próprio movimento da percepção, sendo que é aí, nesse experienciar sensorial, que encontra um sentido. Ou seja, a noção de sentido que aqui se apresenta não é um sentido que se procura formatar, mas é concebido como um exercitar dos micromovimentos da própria percepção que emerge da constante prática na relação corpo-mundo. Este é um sentido pulsante que evidencia e nos dirige ao próprio ânimo da condição viva. Deste modo, a percepção nua não alude a um apelo ao sentido, mas é antes o sentido da força de apelo ao movimento do reciclar corpo-mundo. Como tal, o sentido nu não é um sentido que se determina enquanto forma, mas também não é informe ou sem força, é sim o sentido da força do processo constante de devir corpo - o exercício de incorporar e desincorporar.

Esta noção de percepção nua também encontra fundamento nos estudos sobre consciência de Damásio e Edelman. Damásio (2010) refere que na base da consciência estão os mapas perceptivos relacionados com sistemas de controlo homeostático interno. Edelman (1992) vem-nos demonstrar que estes são sistemas de Valor-Categoria primordiais, que regulam o funcionamento do organismo, e, ao qual, todos os outros sistemas se vão referenciar. Como tal, poderemos considerar que é já ao nível dos mapas dos sentidos interoceptivos que se gera uma concepção orgânica de sentido enquanto um sistema de coerência de valores, ou propósitos reguladores do funcionamento do organismo. Porém, apesar de que, a percepção que aqui se gera demonstra já um sentido de reconhecimento por diferenciação da sensação interna, como Damásio (ibidem) explica, a este nível não existe propriamente uma percepção de consciência de si, apenas aquilo que ele chama de proto-eu. Este nível de percepção poderia ser considerado como uma percepção virgem, pois é uma percepção de corpo como organismo fechado, que ainda não se reconhece. Este será um modo perceptivo que não reflete ainda o movimento intrínseco ao funcionamento corpomundo e logo, esta percepção virgem como corpo impenetrado pelo mundo revela-se como uma impossibilidade.

É então no movimento de interação do proto-eu com os mapas proprioceptivos e exteroceptivos que se gera aquilo que Damásio (2010) denomina como consciência do eunuclear. O eu-nuclear surge assim de um primeiro nível de percepção de corpo-mundo gerado pelo constante pulsar que ocorre na incessante modificação do proto-eu pela interação do organismo com o mundo. Este é assim um modo perceptivo do movimento interativo intrínseco ao processo de corporear, i.e., um modo perceptivo que manifesta um sentido de movimento interativo, enquanto um sentido que relaciona e adapta os valores de diferenciação dos mapas interoceptivos na sua relação com os mapas proprioceptivos e exteroceptivos. Ao longo da evolução, estes dois sistemas ligam-se de modo que as suas atividades pudessem corresponder uma à outra e permitindo uma adaptação a ambientes cada vez mais complexos, explica Edelman (1992). Este é um processo inevitável de aprendizagem evolutiva 
a que Edelman denomina de processo de Categorização Perceptiva do Organismo ${ }^{2}$. A este nível de percepção denomino como percepção nua, pois estamos perante um sentido perceptivo de processo de vida enquanto movimento pulsante de interação com o mundo. Com a noção de percepção nua não quero dizer que será a primeira vez que o organismo sente a diferenciação, por exemplo, entre o sentido de mole e duro ou de dentro e fora, mas sim que a percepção destes sentidos se vai revelando como um contínuo renovar ou redescobrir do sentir. Ou seja, o sentir sensorial não é algo estático ou acabado, pois ocorre temporalmente de modo contínuo. Ele revela-se em estado de devir, enquanto um estado de movimento intensivo e como tal, revela-se em constante recriação.

Resta-me ainda considerar um terceiro nível perceptivo, a que chamaria de percepção vestida. Este é um modo de percepção que se contém sob as vestes conceptuais, em que a realidade se apresenta sob formas de reconhecimento definíveis, ou seja, uma percepção que reconhece um conceito final projetado na forma. Este modo de percepção será aquele que se associa à consciência autobiográfica referida por Damásio (2010) ou a consciência elaborada referida por Edelman (1992). Diria assim que é um modo perceptivo que integra sentidos secundários que se vêm associar ao pulsar da percepção momentânea. Ou seja, é um movimento perceptivo que incorpora um registo de sentidos prévios contraídos num valor cristalizado em experiências anteriores ou na experiência antecipada de futuro ou ainda como sentido armazenado em relações simbólicas.

Em suma o exercício da percepção nua que aqui considero pode ser concebido como um exercício de construção do sentimento de si correspondente ao modo perceptivo donde surge o eu nuclear de Damásio (2010), o qual se baseia no modo como a relação de mapas sensoriais interoceptivos, exteroceptivos e proprioceptivos refletem uma construção de valores homeostáticos inerentes ao próprio funcionamento do organismo. Deste modo, da percepção nua advém um sentido primordial que incorpora uma vontade ou pulsão manifesta na dinâmica de forças do movimento da relação corpo-mundo.

É ainda relevante realçar que a percepção nua não é meramente uma percepção sensorial, pois esse sentido sensorial envolve um movimento pulsante, anímico que surge na relação corpo-mundo e como tal compreende uma condição/ natureza relacional. Como vimos, esta relação corpo-mundo não é uma relação pelo movimento enquanto deslocamento, mas é uma relação pré-pessoal de afetos e micromovimentos de vibração, ou, como explica Manning (2009) no seu livro Relationscapes: Movement, Art, Philosophy, é da própria relação

2 Edelman explica que o aparecimento da consciência primária compreende um desenvolvimento evolutivo, o qual consiste num circuito reentrante que permite a contínua comunicação entre a memória de valor-categoria e as cartografias globais em curso, relativas à categorização percetiva em tempo real. Ao longo da contínua aprendizagem evolutiva e individual surgem experiências carregadas de valor, formando-se um sistema de memória conceptual ou memória de valor-categoria, capaz de categorizar respostas nos diferentes sistemas cerebrais que procedem à categorização percetiva. 
que advém uma nova força animada, um movimento de vida. Manning concebe uma noção de movimento que deriva de forças de relações - "relationscapes", conceptualizando movimento como eventos donde deriva o sentido de tempo e espaço. Também Merleau-Ponty (1999) sublinha a importância de acrescentar a experiência das relações à experiência das qualidades. Ou seja, o sentido nu não se dá apenas como uma pura experiência de qualidades, mas este experienciar qualitativo tem a sua força animada na experiência prépessoal de afetos e seu movimento relacional.

Na sua índole de movimento de relação, o sentido nu não se deixa vestir ou formatar por padrões de referência predeterminados, e como tal, a voz artística que denomino como Arte Sensorial procura uma comunicação que ocorre através de uma percepção de afetos e micromovimentos em vez de signos de comunicação pré-determinados.

\section{Reflexão sobre a obra $A+B=X$, de Gilles Jobin}

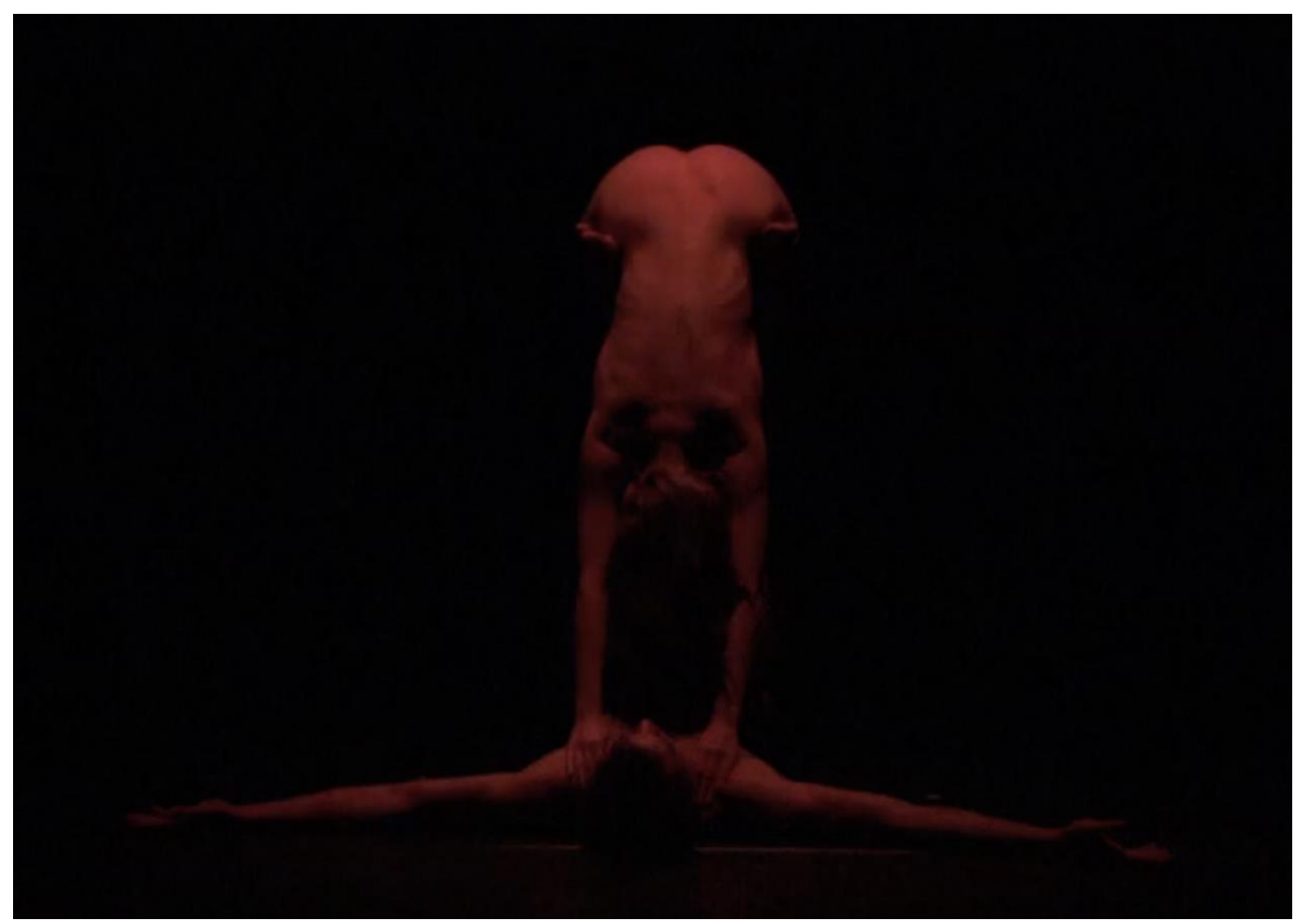

Figura 1 - Imagem retirada do vídeo da obra $A+B=X$, de Gilles Jobin. Disponível em https://vimeo.com/31956034

Tal como Anne Sheppard (1987) defende, esta reflexão tenciona realçar um modo de significar que não pode ser parafraseado ou traduzido; como tal, o que se procura é deixar sobressair o valor artístico na sua capacidade de gerar sentido com a destreza de um simples 
movimento. Para mais, não se pretende abordar o trabalho artístico como algo que necessite de interpretação intelectual, mas sim proclamar um sentido que advém da vivência sensorial da forma. Sendo assim, este é um exercício que procura um modo de interpretação transparente, simplesmente recorrendo à base sensorial do sentido da experiência estética. Esta abordagem é consolidado por Sontag (2001) que declara forma e conteúdo como indissociáveis. Desse modo, parte-se apenas do exercício descritivo daquilo que é intrínseco à obra e não de referências, contextos ou intenções exteriores; estes poderão apenas reforçar o sentido que advém do contexto perceptivo interno. Ou seja, ao invés de uma interpretação intelectual, pretende-se proclamar um sentido que advém da vivência sensorial da forma.

Nesta leitura, foco o fascínio da descoberta do sentido nu provocado pelo jogo perceptivo da obra. Perante tal perspetiva distingue-se um primeiro movimento de in-versão em que o corpo nu se torna cognitivamente despido, e um segundo movimento de per-versão - um movimentar que simultaneamente inverte e revira o verso. Finalmente, contempla-se o enlace entre estes dois movimentos, onde se abre a percepção de um espaço paradoxal de constante re-conhecimento.

\section{O BACKGROUND CONTEXTUAL}

$A+B=X$ é uma obra do coreógrafo suíço Gillles Jobin, estreada a 4 de dezembro de 1997, no Festival Les Urbaines em Lausanne, na Suíça. A música da peça é de Franz Treichler e de The Young Gods. É uma peça criada para palco, com três bailarinos (duas mulheres e um homem) que explora a percepção da nudez, intercalando momentos de projeções vídeo com performance ao vivo. ${ }^{3}$

Gilles Jobin nasceu em 1964 na Suíça e atualmente vive e trabalha com a sua companhia de dança em Genebra. Com esta peça, Jobin tornou-se internacionalmente reconhecido, após o que se seguiram outras obras de grande impacto no mundo da dança e da performance arte, como: Braindance (2000) ${ }_{2}$ Moebius Strip (2001) e Spider Galaxies (2011). A direção radical do seu trabalho artístico tem levado a que seja considerado como um precursor da nova geração de coreógrafos Europeus. Em 2012 foi-lhe concedido o primeiro prémio em dança e performance da Collide@Cern ${ }^{4}$, em Genebra, para desenvolver a sua proposta de explorar a relação entre corpo e mente no maior laboratório do mundo de partículas físicas. Mais recentemente tem criado diversos trabalhos onde combina dança com novas tecnologias multimídia, como por exemplo: Cosmogony e La Comédie Virtuelle. Para

3 Vídeo da peça disponível em: https://vimeo.com/31956034

4 A Collide Cern é um programa artístico do CERN - um dos maiores laboratórios científicos internacionais de física. Este programa seleciona artistas internacionais de diversas áreas, para uma residência totalmente financiada, a qual visa a criação artística em interação com os laboratórios científicos do CERN envolvidos em investigação da física de partículas e física do cosmos. Link: https://arts.cern/artist/gilles-jobin. 
além das suas próprias produções, Jobin tem vindo a potencializar a sua companhia e espaço de trabalho como uma plataforma pioneira para o reconhecimento da dança contemporânea na Suíça, promovendo intercâmbios internacionais, workshops e residências artísticas, tal como projetos com países do hemisfério sul.

\section{EM MODO DE ABERTURA:}

Poderando que a peça explora o descobrir de um modo de fazer sentido gerado pela passagem entre a percepção do nu e do vestido, poderá considerar-se que esta obra se estrutura em duas seções abordadas enquanto dois movimentos que se entrelaçam: os movimentos de in-verter e per-verter a percepção da nudez. Como modo de enquadramento artístico destes movimentos, distingue-se ainda uma parte em modo de abertura e outra como que em modo de remate conclusivo em aberto.

A peça inicia com a projeção de um filme Super 8 que mostra três faces que nos olham de modo simultaneamente direto e alienado. O som contínuo do mecanismo projetor que se desenrola sobrepõe-se com um som mecânico cadenciado. Em tempos diferenciados, expressões e sorrisos forçados são rapidamente cortados com um olhar sisudo; uma mão estranha coça o queixo levantado. Há um jogo quase infantil com as distorções e o disforme dos músculos que produzem esgares no limiar da estranheza. As três faces, que parecem ser da mesma pessoa, olham-se entre si, parecendo reconhecerem-se através de um bizarro cumprimento formal. Por fim, por breves instantes, no lugar das faces aparecem torsos. Produz-se um reconhecimento perturbador da estranheza do profundamente familiar. Este contínuo estado de tensão hipnótica criado pela estranheza do profundamente familiar é algo que subtilmente se vai patenteando enquanto força tónica ao longo da peça.

\section{PRIMEIRO MOVIMENTO: IN-VERSÃO}

Esta secção desenrola-se através de quatro partes, ao longo das quais uma exposição simultaneamente genuína e neutra do corpo nu abre a sua natureza provocatória e subverte a sua expressividade enquanto manifestação familiar.

Um blackout dá lugar a um novo cenário. Agora surge uma atmosfera com uma luminosidade obscura que manipula a percepção e com um ambiente sonoro alucinante, repetitivo, algo inquietador.

Num primeiro momento (agora ao vivo), distingue-se as pernas e nádegas de três torsos nus invertidos. Os três corpos movem-se em uníssono com movimentos lentos, mas precisos, em que o suporte gravítico do chão parte frequentemente de uma relação física de inversão (com pés para cima). Com a cabeça e a parte superior do tronco praticamente imperceptíveis, a coreografia foca o olhar na pélvis e pernas. Os vários momentos de posições invertidas 
produzem um especial realce para as nádegas. Ecoa então um mistério atrativo das nádegas que parecem inebriar o discernimento racional: como podem dois montinhos de carne que se juntam numa direção e se separam na outra, exercer tal fascínio?

Através de outro blackout a peça apresenta um novo quadro em que várias imagens são projetadas no torso dos performers: entre formas quase imperceptíveis distingue-se um olho que nos observa. Num jogo de procura de sentido, Jobin agita com a simplicidade primária de um sentido puro autorreflexivo, gerado pelo poder provocatório do corpo. Tal como explicita: "The body as sculpture, the body as speech, the body as meaning, the images generated suggest more than they say. It is up to the viewer to look into his own self in order to give the presented images their true significance" (JOBIN, 1997). Olham-se corpos que podem refletir / tornar-se qualquer coisa, mas, é na tensão de ser olhado que o corpo se reflete em si próprio.

Segue-se então uma espécie de dueto, um corpo que suporta outro com os pés e as mãos esculpindo o movimento de um torso invertido, suspenso. No seu movimento lento de transfiguração ele suscita um espaço de apreciação do puro poder sensorial do nu. Neste espaço, a percepção do corpo nu oscila entre uma identificação da criatura humana e um irreconhecível estado de vibração da forma, cor, texturas, movimentos.

Esta primeira parte completa-se com um quadro vivo de um corpo nu a solo, que mais uma vez parte de uma posição invertida, com nádegas para cima e o suporte sobre as mãos e pés. Mas agora na visão de nudez surge um novo elemento: os pés não estão descalços, mas sim cobertos por uns ténis pretos... Nesta atmosfera imersiva a índole elástica da carne enuncia-se em torções e distorções de planos de referência habituais: a frente do corpo tornase simultaneamente trás e a relação entre direita, esquerda, cima e baixo flutua continuamente. Mas também a índole de expressão é aqui contorcida, pois ao mesmo tempo que o movimento das nádegas espetadas para cima ganha uma eloquência algo constrangedora, a face, voltada para baixo, articula palavras imperceptíveis com uma neutralidade inexpressiva.

Nesta primeira parte a peça expõe um estado de nudez transparente, mas não vulnerável; explícita, mas sem tocar a pornografia; sexual mas não necessariamente feminina ou masculina; indefinidamente expressiva e simultaneamente delicada e pujante,. Como diz Salas (1998, p. 1), em $A+B=X$ a nudez "questions the basis of human physical representation". Ecoam corpos que se vestem apenas da sua nudez, sem intenção inerente, eles são apenas a ambivalência latente da carne que vive. Na sua manifestação de ambivalência impossível de agarrar eles produzem uma atenção suspensa, em tensão. É uma tensão preceptiva, em que a fisicalidade plástica da carne e pele que se vai disformando e transformando produz um forte apelo sensorial. Os corpos nus, descontextualizados, sem materialização de desejo são provocadores de um despertar da sensação pura. Corpos que, como Jobin (1997) expressa, 
"speak a strange language that corresponds to nothing but which means so much". Nesta viagem entre o profundamente familiar e o profundamente estranho cria-se tempo e espaço para redescobrir um sentido sensorial indefinível. A tensão preceptiva gera-se então na oscilação constante entre um reconhecimento de si como expressão de um corpo e como matéria vibrante despersonalizada. Todavia, a obra não fica por aqui. Segue-se uma segunda parte que vai jogar com um movimento perceptivo de per-versão.

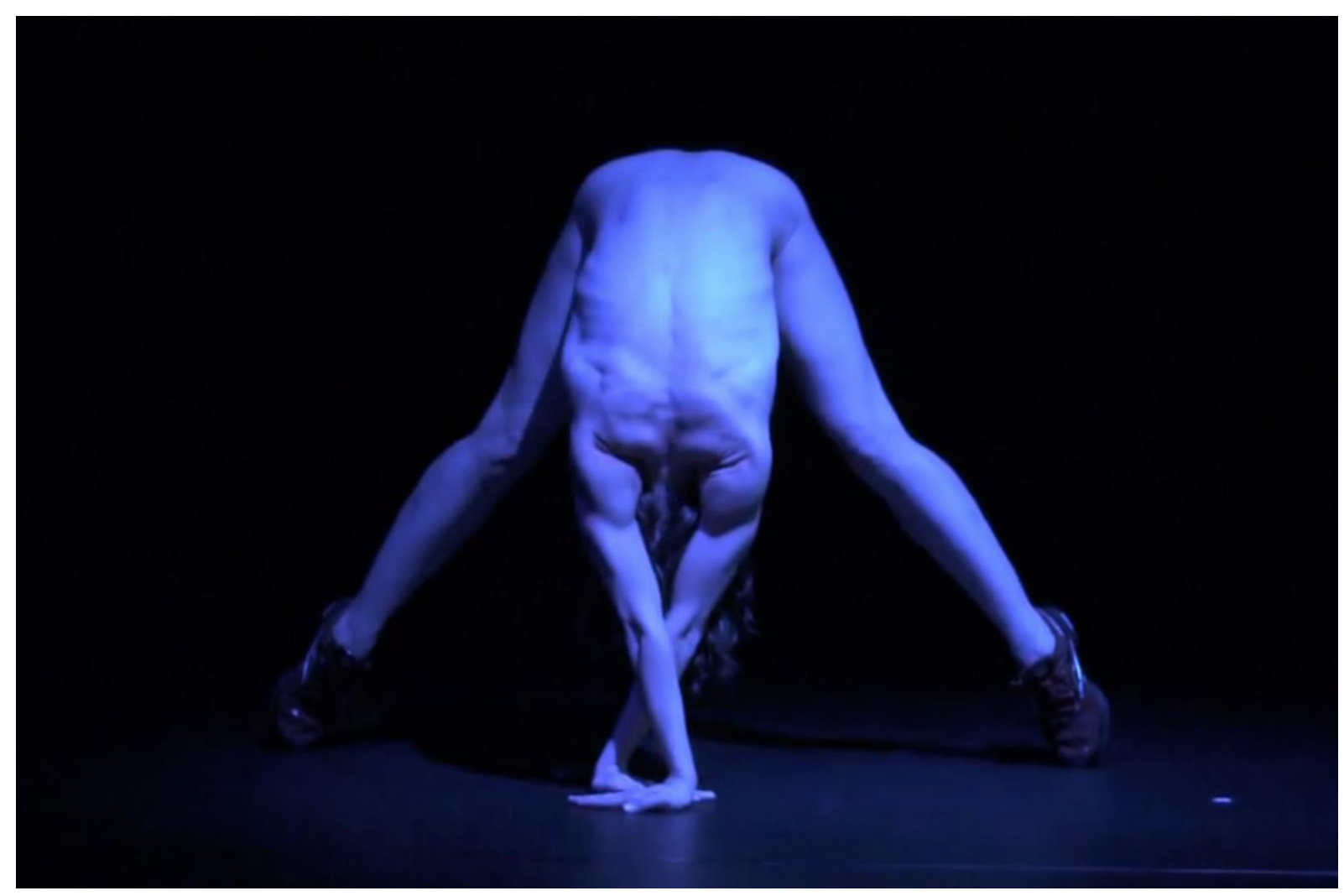

Figura 2 - Imagem retirada do vídeo da obra $A+B=X$, de Gilles Jobin. Disponível em https://vimeo.com/31956034

\section{SEGUNDO MOVIMENTO: PER-VERSÃO}

Esta segunda parte inicia-se com o retomar de uma projeção de filme Super 8, mais uma vez com o ambiente sonoro do mecanismo projetor que vai desenrolando. São projetados três corpos nus simplesmente verticais que giram sobre si expondo-se de frente e de trás. $A$ nudez torna-se agora crua. Uma vez de costas eles coçam as nádegas num gesto casual, remetendo ao coçar inicial do pescoço. Mas agora estas mãos que tocam não são estranhas, o gesto é tão familiar que se torna quase inconsciente. O coçar remete a um ato intuitivo, mas imperativo de reconhecimento do próprio corpo. Através deste paralelo gestual, as nádegas 
afiguram-se mais familiares do que o rosto, como uma outra superfície carismática de reconhecimento.

Os três corpos iniciam depois a ação de vestir, porém há algo desconexo, incoerente com esta ação: apesar de os corpos se irem cobrindo com roupa, o movimento parece ser o de despir! Afinal, este filme desenrola-se em reverso. Neste reverter do movimento, o vestir torna-se um exercício de despir, porquanto ao vestir-se o corpo despe-se de si mesmo, ou seja, ele desnuda-se da sua crueza de corpo em devir e assume-se enquanto individuo social.

De seguida, já vestidos com roupas casuais, os três indivíduos projetados desvanecem para dar lugar aos mesmos indivíduos ao vivo. Eles assumem uma posição de atletas de sprint e começam uma energética sequência coreográfica em uníssono ao som de The Young Gods. Os movimentos, inicialmente bastante verticais, são como que uma sequência banal de ginástica aeróbica. Como Frétard (1999) refere no seu artigo para o jornal Le Monde, a peça não se fecha sobre uma atmosfera cerimonial transgressiva, mas a banalidade também faz parte da sua matéria. Agora, uma aparente descontração trivial dos corpos vestidos parece opor-se à tensão subtil do nu. Porém, ao mesmo tempo em que expõe esta oposição óbvia, a obra ecoa mais uma vez o distorcer e inverter subtil do modo de percepção. Ao vestir, os corpos deixam de se revelar como corpo-mundo em devir, simultaneamente intimo e estranho, para se manifestarem como indivíduos. Esta transição reflete um movimento de contração: como se os poros da pele se fechassem sob as camadas de roupa numa con-tensão material sobre si.

A certa altura, dois performers saem, ficando apenas um deles gatinhando. Sobre ele desenha-se um círculo de luz no chão; a parte instrumental da música de The Young Gods continua com um forte pulso energético. Apoiando a cabeça no chão, ele baixa as calças expondo o rabo para cima e abanando-o de um lado para o outro, a seguir, começa a saltar energeticamente à volta do círculo, sempre com o suporte das mãos e pés no chão e o rabo de fora. Surge aqui uma forte associação com movimento primário de um símio delimitando território com toda a sua pujança energética.

Este quadro suscita abertamente um movimento que agita e confronta a percepção sensorial nua com a percepção vestida que se prende a juízos morais. A empatia sensorial e energética deste gesto primário e visceral entra em choque com uma natureza tácita do juízo moral e social que classifica o ato intencional de expor o rabo como um ato obsceno. Neste limiar, o modo perceptivo, confronta-se e questiona-se a si próprio.

Como se todos os entrelaces de distorções e inversões anteriores se contivessem agora num único ponto que se torna racionalmente indiscernível mas intuitivamente elementar, entra-se agora num exercício intuitivo não de perversão, mas de per-versão, ou seja, um movimentar que simultaneamente inverte e revira o verso. 
Após tal momento vertiginoso, a peça respira através de uma simples imagem de nudez frontal crua. Através de dois focos de luz que gradualmente são deslocados para a frente do corpo, desmistifica-se o modo como esta nudez crua se vai tornando quase imaterial.

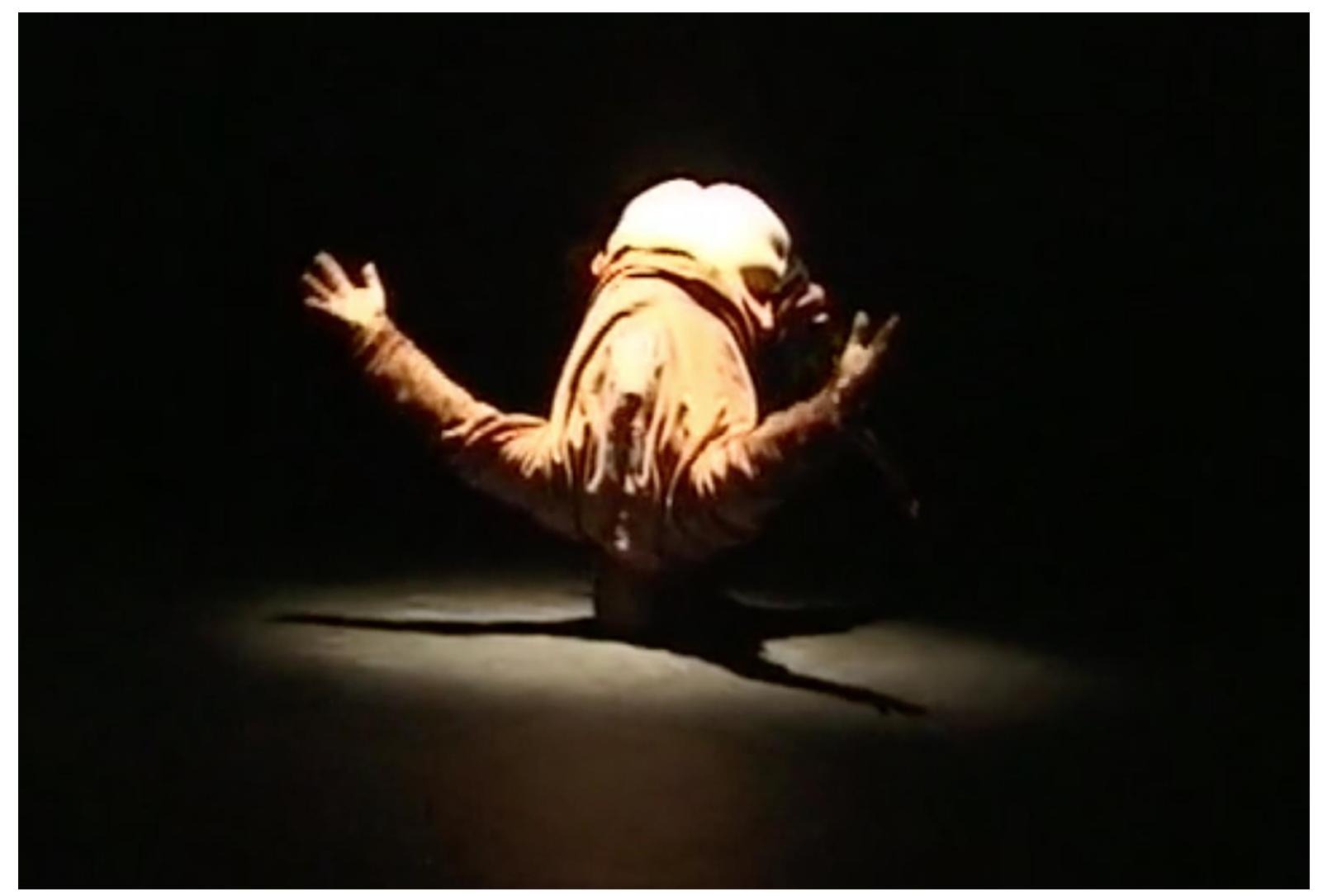

Figura 3 - Imagem retirada do vídeo da obra $A+B=X$, de Gilles Jobin. Disponível em https://vimeo.com/31956034

\section{DESFECHO DA PEÇA: ABRIR O ESPAÇO PARADOXAL}

A peça termina com uma última projeção: agora surge uma voz associada a uma imagem arrepiante de um homem de lábios cozidos e corpo tatuado (pertencentes ao performer de Body Art, Franco B). Com o peso desta imagem, uma voz-off discursa uma visão em aberto sobre o que é a arte. Mais uma vez se joga um jogo de manifestações aparentemente contraditórias: "O que é a arte?" Questiona a voz. "Depende a quem se pergunta... Pode ser qualquer coisa... Sobreviver é uma arte... Arte é muito estranho, confuso... como uma comichão..."

Neste espaço intangível da relação per-versa entre os limites da carne e do verbo, entre um texto cândido e uma imagem chocante, $A+B=X$ finaliza com uma provocação a nu do exercício da arte enquanto um jogo com as fronteiras da percepção englobando todos os sentidos - tal é a expressão de Jobin em entrevista a Francis Cossu: " $A+B=X$ joue beaucoup avec les frontières de la perception, englobe tous les sens" (COSSU, 2010). O desafio do 
público é precisamente essa indagação sobre a natureza do sentido, essa procura de modos de fazer sentido. $A+B=X$ provoca um modo de fazer sentido que surge da percepção nua para depois confrontar esse sentido nu com a percepção vestida ou pré-determinada.

\section{DESFECHO DA REFLEXÃO SOBRE $A+B=X$}

O jogo de limite perceptivo desta peça é um processo intrínseco de re-conhecimento contínuo que abre um espaço paradoxal. Ao se agitar nas fronteiras da percepção do sentido do nu, a obra suscita um outro movimento perceptivo exponencial: o movimento entre uma percepção nua e uma percepção vestida.

A obra joga com o espaço de transmutação entre estes dois modos perceptivos: o corpo inicialmente reconhecido como conceito corpo torna-se abstrato, distanciando-se do préreconhecível para suscitar um outro tipo de conhecimento. Este é um conhecimento que surge da intensificação sensível da matéria. Gera-se então uma faculdade de conhecer reflexiva, ou seja, em constante movimento vibratório entre um reconhecimento sensorial do corpo através da matéria sensível do mundo, e o reconhecimento do mundo através dos sentidos. Neste movimento do sensível a matéria anima-se, ganha força. O conhecimento torna-se um constante movimento de re-conhecimento (De Lima, 2017).

Em última análise, não é especialmente o corpo que se despe e veste, mas o modo perceptivo. Será neste movimento paradoxal em que o vestir se torna um exercício do nu, e o despir um exercício do vestido, que a arte trabalha o jogo do conhecimento?

\section{Aprofundar o sentido nu através da confrontação entre duas obras coreográficas}

$\mathrm{Na}$ intensificação da percepção sensorial encontra-se, pois, um sentido nu. Mas, qual a índole deste grau zero de sentido ou da percepção nua que aqui pretendo evidenciar; como contextualizá-lo?

Para abordar esta questão mais a fundo irei confrontar a reflexão acima exposta sobre a peça $A+B=X$, de Gilles Jobin, com o artigo escrito por Una Bauer (2008), intitulado: The Movement of Embodied Thought The Representational Game of the Stage Zero of Signification in Jérôme Bel, o qual faz uma análise da peça Jérôme Bel criada pelo coreógrafo francês Jérôme Bel ${ }^{5}$, estreada em 1995 no Bellones-Brigittines Festival (Bruxelas).

5 Jérôme Bel, nasceu em 1964 em França. Estudou dança no Centro Coreográfico Nacional de Angers. Entre 1985 e 1991 dançou com diversos coreógrafos, incluindo Angelin Preljocaj, Régis Obadia e Caterina Sagna. Em 1992 foi assistente de Phillippe Découflé na cerimónia dos Jogos Olímpicos de Inverno em Albertville. Trabalhou doze anos com Frédéric Seguette. Tornou-se uma das figuras centrais do movimento artístico conhecido como "non-dance". O seu trabalho tem sido apresentado não só em salas de teatro e festivais internacionais de artes performativas como também em diversos museus e bienais de arte contemporânea (Tate Modern, MoMA, Documenta 13, Louvre). Em 2005 ganhou o 
O coreógrafo Jérôme Bel expressa que o esforço de representar o grau zero de significação é sempre uma tentativa insuficiente - "the neutral or stage zero can never be neutral enough, zero enough" (Bauer, 2008, p. 39). Ao deparar com esta tentativa torna-se óbvio que o corpo nu nunca é um corpo neutro, de significação zero. O corpo nu expõe em si um sujeito marcado não só pelas suas características biológicas, mas também pela experiência que em si arquiva. No seu artigo, Bauer demonstra que, na aparente tentativa de representar o grau zero da dança, esta peça expõe antes um intuito propositado e provocatório de questionar uma representação do grau zero de significação. No centro provocatório e inquiridor desta obra está a tensão provocada pelo corpo nu e pela percepção do simples ato de urinar em palco. Como mostra Bauer, esta obra não tem meramente o intuito de substituir a representação convencional de urina (como algo nojento) por uma outra representação menos convencional, a qual iria fixar a noção de urina a um outro mecanismo representativo (associado a ideias de liberação, expressão interior, libertação de opressão social, etc.). Em vez disso, a peça "stages a dialogue between the two, between our possible understanding of them [...] The two positions, in Bel's performance stand in a dialogical relationship" (idem, p. 41). Ao lidar com a tentativa de neutralidade em palco, o que a obra procura induzir é pois um "movement of an embodied thought" (idem, p.39). Por outras palavras, ao testemunhar esta performance, entra-se num movimento entre dois polos de sentido representativo: o rasgar do convencional tentando conceber urina como algo neutro associado ao ato de urinar em palco como algo libertador, e a dificuldade ou incapacidade em conceber tal e livrar-se de um sentido convencional já incorporado.

Bessie, em Nova York, com a obra The Show Must Go On. Em 2013, ganhou o prémio suíço "PresentDay Dance Creation", com a peça Disabled Theater. 


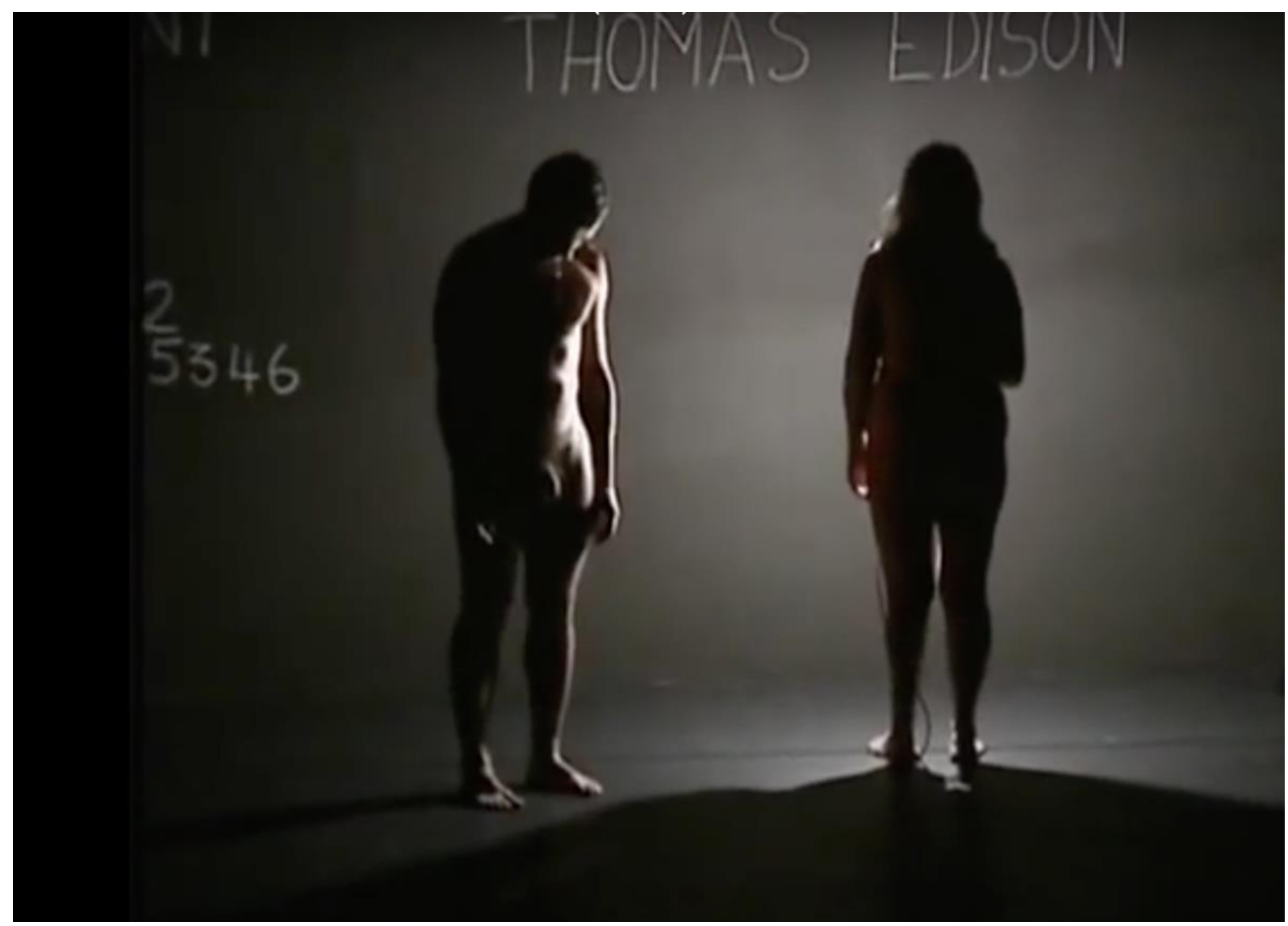

Figura 4 - Imagem retirada do vídeo da obra Jérôme Bel de Jérôme Bel. Disponível em https://www.youtube.com/watch?v=9Aggn9IMxTQ

Ora, esta obra lida com um movimento na percepção de signos ou sentidos que se convencionam, ou seja, movimentos entre modos de vestir a percepção. Estamos aqui perante um domínio de procura de sentidos projetados num conceito, numa representação ou num símbolo. Perante esta peça, a percepção de corpo, de urina, de música, dança, etc. não são sentimentos primordiais ou meras sensações. Elas envolvem diversas camadas de sentido: experienciais, culturais, sociais, etc. Quero com isto dizer que nesta obra olha-se para corpo, urina e o ato de urinar através de uma perspetiva que considera um sentido em tensão entre objeto-sujeito e não para a capacidade de movimento intrínseca à percepção. Ou seja, não se contempla aqui o exercício da percepção sensorial de cheiro, cor, textura etc., mas sim a percepção projetada sobre o conceito objeto-sujeito contemplado por signos como urina, corpo, dança etc.

De facto, como realça Bauer, com esta obra Bel procura instigar um movement of embodied thought; mas este é essencialmente um movimento do pensamento entre dois pontos onde a percepção se fixa. Porém, o sentido nu que procuro aqui não é um sentido presente na natureza representativa do gesto, do signo ou do conceito, mas sim um sentido 
presente nas dinâmicas vitais do movimento da própria natureza sensorial. Deste modo, não é um sentido que se move entre dois pontos fixos relativos ao plano de macromovimentos sujeito-objeto, mas sim um sentido dos micromovimentos intrínsecos ao próprio movimento que compõe a capacidade de percepção. Por isso, diria então que o que procuro aqui não é tanto um movement of embodied thought, mas sim o exercício de Embodied Movement Thinking - Pensamento Incorporado em Movimento. É a própria capacidade de percepção intrínseca à capacidade de pensar que revela o movimento como motor de sentido. É este movimento que penso que Gilles Jobin consegue fazer exercitar na sua obra $A+B=X$.

A obra de Gilles Jobin não se foca na dialética entre domínios convencionais de sentido e a ambição explícita de rasgar convenções. É também o corpo nu que está presente, mas este não se representa, apenas está presente, e com a sua presença apresenta um poder de provocação sensorial. O corpo nu não é aqui um objeto-sujeito, pois não pertence a qualquer domínio; ele é simplesmente uma força provocadora de sentidos. O corpo que o espectador observa torna-se um provocador ou intensificador do sentir de sentidos sensoriais, e como tal, o que está em jogo não é o sentido associado ao corpo como signo de si mesmo, mas sim as pulsões ou micromovimentos da tensão sensorial provocada. Nesta obra o nu não representa um grau zero de sentido, pois não se joga aqui com a representação de sentidos, mas sim com o sentir de sentido. Joga-se com a intensificação de sentido sensorial que o corpo nu incita, joga-se com a tensão sensorial intrínseca à carne viva do corpo. Assim sendo, é ainda importante distinguir que esta peça não questiona diretamente as fronteiras de sentido enquanto significado pré-definido, mas sim, como afirma Jobin (1997), ela joga com as fronteiras da percepção englobando todos os sentidos sensoriais e sinestesias de sentidos.

Como vimos acima, o sentido nu descobre-se no pulsar perceptivo. Este é o pulsar do eu-nuclear de Damásio (2010), no qual se relacionam e adaptam os valores de diferenciação dos mapas interocetivos com os mapas propriocetivos e exterocetivos, e como tal, é o pulsar de um sentido que se gera no movimentar interativo corpo-mundo intrínseco ao funcionamento do nosso organismo. É este movimento pulsante do eu-nuclear que Jobin consegue estimular.

Entretanto, a obra não joga apenas com o movimento de percepção a partir do corpo nu, joga igualmente com a percepção do corpo que procura vestir-se, e perante este quadro, surge um movimento perceptivo paradoxal. O vestir torna-se um exercício de resistência, um exercício do impossível, porque o corpo não consegue esconder totalmente a sua intensidade sensorial, não consegue cobrir a eloquência nua da carne vibrante. O corpo despido procura vestir-se, mas, a prática de vestir reverte-se num exercício de despir - entra-se num loop de forças, de desejos. Ao procurar vestir-se, o corpo tenta penetrar numa outra camada do sentido de si: dança como os outros em uníssono e procura um sentido representativo, tenta identificar-se no autorreflexo de uma dança que veste todos os corpos. Porém, este é um desejo frustrado, pois 
o sentido que agora se tenta construir é um sentido que se agarra a uma sombra, a uma projeção que fixa o sentir sentido. Não é o corpo nu que vem questionar o sentido do corpo vestido, é antes a atração vibrante da matéria viva - aquele pedaço de carne que se des-cobre. Ou talvez seja o ato de vestir e despir a matéria animada que vem questionar a percepção.

\section{Concluindo}

A confrontação entre estas duas obras coreográficas vem convocar dois planos de movimento inerentes à percepção e formação de sentido: o sentido definido, vestido de representações ou símbolos e determinado com percepção dos macromovimentos e o sentido sensorial ou sentido nu que surge com micromovimentos da percepção.

Por um lado, como suscita a obra Jérôme Bel, importa considerar o sentido no seu plano de macromovimentos, no qual se apura uma impossibilidade de conceber sentido no seu estado nu. Estamos aqui no plano da representação: qualquer sentido que aqui se concebe está agregado a um signo no qual se enraíza e afixa. É um sentido incorporado porque está preso nas marcas temporais do corpo, adere ao corpo que se vai fixando a uma linha de tempo. Deste modo, o movimento que aqui se faz é um macromovimento entre dois sentidos que se afixam, é um movimento que provoca uma relação dialógica. Ao fixar a incorporação de sentido no tempo, este é um sentido que não incorpora o movimento no tempo.

Por outro lado, a obra $A+B=X$ de Gil Jobin joga com o sentido no plano de micromovimentos, estes são movimentos que não se fixam no tempo, pois são pulsões e vibrações permanentes. É desse ritmo permanente dos micromovimentos sensoriais que se geram tempos não cronológicos, mas transformativos. A percepção nua é também ela própria o estado vibratório da percepção que não se fixa no macromovimento. Assim se distingue também o sentido nu, não como os possíveis sentidos de um corpo nu, mas sim enquanto um movimento vibratório da própria percepção de sentido, que se agita entre algo que é simultaneamente familiar e estranho.

Assim sendo, a Arte Sensorial não é meramente um fazer que procura sentidos sensoriomotores, ela é ainda um exercício de procura de sentido no plano de micromovimentos, que não deixa a percepção fixar-se a um único sentido, provocando-lhe um movimento vibratório onde o familiar se torna estranho e a matéria viva do corpo se torna intima.

\section{Referências}

BAUER, Una. The Movement of Embodied Thought the Representational Game of the Stage Zero of Signification in Jérôme Bel. Performance Research, v. 13, n.1, p. 35-41, 2008.

DAMÁSIO, António O Livro da Consciência: A Construção do Cérebro Consciente. Lisboa: Circulo de Leitores, 2010.

DE LIMA, Cecília. Sensorial Art: Perceiving the world as e-motion. Danswetenschap in Nederland, v. 6, p.175-179, 2010. 
DE LIMA, Cecília. Pensamento Transversal: A Arte de Experienciar o Mundo como o Paradoxo do Movimento. Tese de Doutoramento (Motricidade Humana, Estudos de Dança). Faculdade de Motricidade Humana, Universidade de Lisboa, 2017.

EDELMAN, Gerald. Biologia da Consciência: As raízes do pensamento. Lisboa: Instituto Piaget, 1992.

FRANCIS Cossu. Interview Gilles Jobin par Francis Cossu. In: CCS Paris 21/10/2010. Disponível em: https://www.gillesjobin.com/wp-content/uploads/2020/07/abx-itw-cossu.pdf. Acesso em: 22/06/2020.

FRÉTARD, Dominique. Three torsos at the boundaries of pornography. In: Le Monde 29/06/1999. Disponível em: https://www.gillesjobin.com/wp-content/uploads/2020/07/abx-le-monde.pdf . Acesso em: 22/6/2020.

GIBSON, James J. The Senses Considered as Perceptual Systems. Connecticut: Greenwood Press, 1966.

GIL, José. A Imagem-nua e as Pequenas Percepções. Lisboa: Relógio d’Água, 2005.

JOBIN, Gilles. $A+B=X$, Presentation. In: Cie Gilles Jobin. Disponível em:

https://www.gillesjobin.com/en/creation/abx/. Acesso em: 22/6/ 2020.

LEPKOFF, Daniel. Contact Improvisation: A Question. Contact Quarterly, Journal of Dance and Improvisation, v.36 n.1, p.38-40, 2011.

MANNING, Erin. Relationscapes: Movement, Art, Philosophy. Cambridge, Massachusetts, London: MIT Press, 2009.

MASSUMI, Brian. Parables for the Virtual: Movement, Affect, Sensation. London: Duke University Press, 2002.

MERLEAU-PONTY, Maurice. Fenomenologia da Percepção. São Paulo: Martins Fontes Editora Lda, 1999.

PAIS, Ana. O Discurso da Cumplicidade: Dramaturgias Contemporâneas. Lisboa: Edições Colibri, 2016.

REYNOLDS, Dee and MATTHEW Reason. Kinesthetic Empathy and Cultural Practices. Chicago: University of Chicago Press, 2012.

SALAS, Roger. The mysterious nude. In: El Pais, 26/10/1998. Disponível em: https://www.gillesjobin.com/wp-content/uploads/2020/07/abx-el-pais.pdf. Acesso em: 22/6/ 2020.

SHEPPARD, Anne. Aesthetics: An Introduction to the Philosophy of Art. New York: Oxford University Press, 1987.

SONTAG, Susan. Against Interpretation and Other Essays. New York: Picador USA, 2001 